\title{
Surgical Options for Pulmonary Atresia with Ventricular Septal Defect in Neonates and Young Infants
}

\author{
Won Young Lee ${ }^{1}$ Seung Ri Kang ${ }^{1} \cdot$ Yu Mi Im $^{2} \cdot$ Tae-Jin Yun $^{1}$ (I)
}

Received: 3 July 2019 / Accepted: 23 April 2020 / Published online: 6 May 2020

○) Springer Science+Business Media, LLC, part of Springer Nature 2020

\begin{abstract}
Background The optimal surgical strategy for pulmonary atresia with ventricular septal defect (PA/VSD) in neonates and young infants is controversial. Staged repair may be associated with a higher risk of inter-stage mortality, while primary repair may lead to frequent post-repair re-interventions.

Methods From 2004 to 2017, 65 patients with PA/VSD who underwent surgical intervention before 90 days of age were identified and enrolled in this retrospective study. The cohort was divided into two groups: group-SR, who underwent initial palliation with staged repair $(n=50)$, and group-PR who underwent primary repair $(n=15)$.

Results There were three post-palliation in-hospital mortalities, four inter-stage mortalities, and one post-repair in-hospital mortality in group-SR. In group-PR, there was one in-hospital death and one late death. Five-year survival rates were comparable between the two groups (group-SR: 83.6\%; group-PR: $86.7 \% ; p=0.754$ ). During the median follow-up duration of 44.7 months (Inter-quartile range, 19-109 months), 40 post-repair re-interventions ( 22 in group-SR, 18 in group-PR) were performed in 26 patients (18 in group-SR, 8 in group-PR). On Cox proportional hazards model, primary repair was identified as the only risk factor for decreased time to death/1 st post-repair re-intervention (Hazard ratio (HR): $2.3, p=0.049$ ) and death/2nd post-repair re-intervention (HR 2.91, $p=0.033$ ).

Conclusions A staged repair strategy, compared with primary repair, was associated with comparable overall survival with less frequent re-interventions after repair in young infants with PA/VSD. Lowering the inter-stage mortality after initial palliation by vigilant outpatient care and aggressive home monitoring may be the key to better surgical outcomes in this subset.

\section{Graphic Abstract}

Surgical outcomes of PA with VSD according to the surgical strategies. Patient 1 (birth weight: $2.7 \mathrm{~kg}$ ) underwent primary Rastelli-type repair at post-natal day \# 50 (body weight: $3.8 \mathrm{~kg}$ ) using Contegra ${ }^{\circledR} 12 \mathrm{~mm}$. The postoperative course was rocky, with long ventilatory support (10 days), ICU stay (14 days), and hospital stay (20 days). Cardiac CT scan at 9 months postrepair showed severe branch pulmonary artery stenosis, which necessitated LPA stenting at 12 months post-repair and RV-PA conduit replacement with extensive pulmonary artery reconstruction at 25 months post-repair. Patient 2 (birth weight: $2.5 \mathrm{~kg}$ ) underwent RMBT at post-natal day \#30 (body weight: $3.4 \mathrm{~kg}$ ) using $4 \mathrm{~mm}$ PTFE vascular graft and staged Rastelli-type
\end{abstract}

Presented at the 55th annual meeting of Society of Thoracic Surgeons, San Diego, CA, January 27-29, 2019

Tae-Jin Yun

tjyun@amc.seoul.kr

1 Division of Pediatric Cardiac Surgery, Asan Medical Center, University of Ulsan, 88, Olympic-Ro 43-Gil, Songpa-Gu, Seoul 05505, Korea

2 College of Nursing, Dankook University, Cheonan, Republic of Korea 
repair at post-natal 11 months using a hand-made Gore-Tex valved conduit $(14 \mathrm{~mm})$. No post-repair re-intervention has been performed. Cardiac CT scan at 90 months post-repair showed no branch pulmonary artery stenosis.

\section{-Outcomes according to the surgical strategies-}

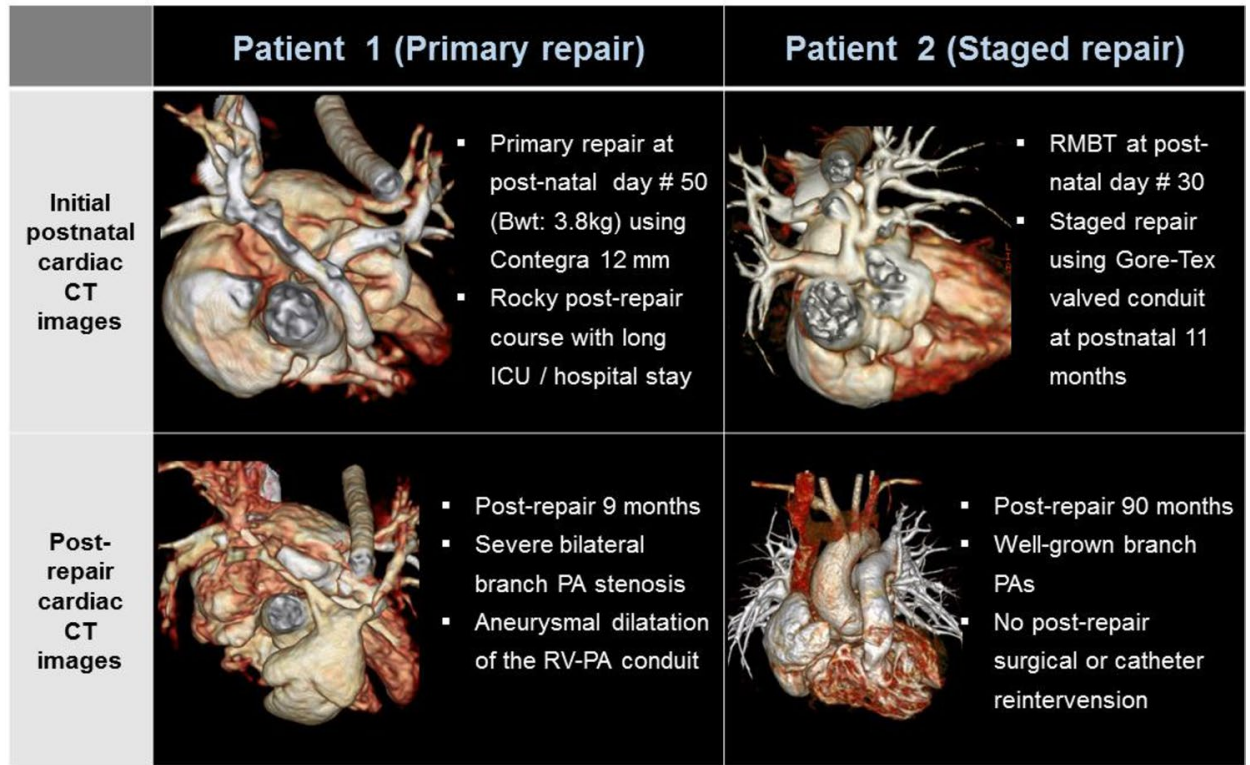

$C T$ computed tomography, ICU intensive care unit, LPA left pulmonary artery, PA pulmonary atresia, PTFE polytetrafluoroethylene, $R M B T$ right modified Blalock-Taussig shunt, $R V$ - $P A$ right ventricle to pulmonary artery, $V S D$ ventricular septal defect.

Keywords Pulmonary atresia $\cdot$ Ventricular septal defect $\cdot$ Early primary repair $\cdot$ Staged repair

\section{Introduction}

Pulmonary atresia with ventricular septal defect (PA/VSD) is a congenital heart defect (CHD) characterized by discontinuity from the right ventricle (RV) to the pulmonary arteries (PAs), as well as a malaligned ventricular septal defect (VSD) caused by anterior displacement of the conal septum [1]. Except PA/VSD patients with major aortopulmonary collateral arteries (MAPCA), simple forms of PA/VSD have ductus-dependent pulmonary circulation requiring early surgical intervention. Surgical options for neonates and young infants with PA/VSD have been under debate. Early primary repairs guarantee the restoration of serial circulation, and may prevent progression of right ventricular hypertrophy (RVH). However, early primary repairs present increased risks of cardiopulmonary bypass (CPB) for young and small patients as well as inevitable placement of a small RV-PA conduit, which necessitates early conduit replacement.

Furthermore, repair with aggressive manipulation of the thin and fragile neonatal pulmonary arterial structures may lead to frequent post-repair surgical or catheter re-intervention on the branch PAs. Initial palliation with staged repair enables neonates to defer the definitive operation until they can undergo repair with relatively lower risks of CPB-associated complications, and larger RV-PA conduit with prolonged durability can be used. However, high in-hospital [2] and inter-stage mortality [3-5] have been considered as caveats of the staged repair strategy. In this study, we sought to determine the impact of surgical strategies on overall survival and the incidence of post-repair re-interventions.

\section{Material and Methods}

\section{Patients}

From 2004 to 2017, 65 patients who underwent surgical intervention for PA/VSD before reaching 90 days of age were identified and enrolled in this retrospective study. Patients with MAPCAs were excluded, and pulmonary circulation of all patients was dependent on ductal patency prior to the initial operation. There were 28 males, and prematurity (gestational age $<37$ weeks) was present in 13 patients. The cohort was divided into two groups: group-SR, in which patients underwent staged repair after initial palliation $(n=50,28$ 
males), and group-PR, in which patients underwent primary repair ( $n=15$, nine males). Comparison of the patient characteristics at birth, at initial operation, and at repair between the two groups are summarized in Table 1.

In group-SR, the median age at initial palliation was 22 days (Inter-quartile range (IQR): 16-36 days). Because the median birth weight of the patients in group-SR was $2.75 \mathrm{~kg}$ (birth weight $<2.5 \mathrm{~kg}$ in 17 patients; lowest birth weight: $910 \mathrm{gm}$ ), most of the patients were put on prostaglandin E1 for several weeks prior to the palliative procedures to prevent palliation-induced pulmonary overcirculation. Median body weight and pulmonary artery index (Nakata index) at palliation were $3.3 \mathrm{~kg}$ (IQR: $3.0-3.6 \mathrm{~kg}$ ) and $116 \mathrm{~mm}^{2} / \mathrm{m}^{2}$ (IQR: $90-143 \mathrm{~mm}^{2} / \mathrm{m}^{2}$ ), respectively.

The most common type of palliation was the right modified Blalock-Taussig (MBT) shunt $(n=42)$, followed by right ventricle to pulmonary artery (RV-PA) conduit placement $(n=4)$, left MBT shunt $(n=2)$, and central shunt $(n=2)$. MBT shunts utilized a thoracotomy approach via the 4th intercostal space, and placement of the RV-PA conduit and central shunts were performed via full median sternotomy. For the shunt procedures, polytetrafluoroethylene (PTFE) tube grafts (Gore-Tex vascular graft, W.L. Gore assoc. Inc, Elkton, MD) of appropriate size were used. The most commonly used shunt size was $3.5 \mathrm{~mm}(n=37)$, followed by $4 \mathrm{~mm}(n=8)$, and $3 \mathrm{~mm}(n=1)$. For RV-PA conduit placement, 5-7 mm sized PTFE tube grafts were used. Additional palliative procedures prior to the repair were necessary for three patients: RV-PA conduit placement in two patients, and right MBT shunt in one patient. Excluding post-palliation in-hospital mortality $(n=3,6 \%)$ and interstage mortality $(n=4,8 \%)$, and staged Rastelli-type repair was performed in 43 patients at a median interval period of 9.4 months (IQR: 6.3-11.7 months) after initial palliation. Median age, body weight, and Nakata index at Rastelli-type repair was 10.1 months (IQR: $8.0-12.4$ months), $8.0 \mathrm{~kg}$ (IQR: $7.2-10 \mathrm{~kg}$ ), and $193 \mathrm{~mm}^{2} / \mathrm{m}^{2}$ (IQR: $153-258 \mathrm{~mm}^{2}$ / $\mathrm{m}^{2}$ ), respectively. Types of RV-PA conduit comprised nonvalved PTFE conduit in 10, bovine jugular vein graft (Contegra; Medtronic, Inc, Minneapolis, Minn) in 10, Hancock valved conduit in 9, hand-made PTFE membrane-valved conduit [6] in 7, and miscellaneous in 3 . In four patients with membranous pulmonary atresia, a transannular patch was placed without the use of extracardiac conduit.

In group-PR, median age, body weight, and Nakata index at Rastelli-type repair was 29 days (IQR: $12-50$ days), $3.4 \mathrm{~kg}$ (IQR: $3.3-4.0 \mathrm{~kg}$ ), and $175 \mathrm{~mm}^{2} / \mathrm{m}^{2}$ (IQR: $109-200 \mathrm{~mm}^{2} /$ $\mathrm{m}^{2}$ ), respectively. Types of RV-PA conduit included bovine jugular vein grafts in six patients, non-valved PTFE conduits in four patients, and a hand-made PTFE membrane-valved conduit in one patient. In four patients with membranous pulmonary atresia, a transannular patch was placed without the use of an extracardiac conduit. This study was approved by the Institutional Review Board (IRB No.: S2019-0119), and the need for informed consent was waived due to the retrospective nature of the study.

\section{Statistical Analysis}

Data are presented as frequencies with percentage and median with ranges. A Kaplan-Meier curves with a 95\% confidence interval were plotted for each group to delineate overall survival, freedom from death or 1st post-repair re-intervention, and freedom from death or 2 nd post-repair
Table 1 Patient characteristics of the two groups

\begin{tabular}{lllr}
\hline & Group-SR & Group-PR & $p$ value \\
\hline At birth & $(n=50)$ & $(n=15)$ & \\
Birth weight, $\mathrm{kg}$ (median, range) & $2.64(0.91 \sim 3.75)$ & $2.85(1.63 \sim 4.33)$ & 0.27 \\
Prematurity $(\mathrm{GA}<37$ weeks) & $10(20.0 \%)$ & $3(20.0 \%)$ & $>0.99$ \\
Sex, male & $22(44.0 \%)$ & $6(40.0 \%)$ & $>0.99$ \\
Nakata index, $\mathrm{mm}^{2} / \mathrm{m}^{2}$ (median, IQR) & $129(97 \sim 156)$ & $139(82 \sim 188)$ & 0.70 \\
At initial operation & $(n=50)$ & $(n=15)$ & \\
Nakata index, $\mathrm{mm}^{2} / \mathrm{m}^{2}$ (median, IQR) & $116(90 \sim 143)$ & $175(109 \sim 200)$ & $<0.01$ \\
Age at operation, days (median, IQR) & $22(16.0 \sim 36)$ & $29(12 \sim 50)$ & 0.22 \\
Weight at operation, $\mathrm{kg}$ (median, IQR) & $3.3(3.0 \sim 3.6)$ & $3.4(3.3 \sim 4.0)$ & 0.12 \\
At Rastelli-type operation & $(n=43)$ & $(n=15)$ & $<.001$ \\
Age, months (median, IQR) & $10.1(8.0 \sim 12.4)$ & $1.0(0.4 \sim 1.6)$ & $<.001$ \\
Weight, kg (median, IQR) & $8.0(7.2 \sim 10.0)$ & $3.0(3.3 \sim 4.0)$ & 0.05 \\
Nakata index, mm ${ }^{2} / \mathrm{m}^{2}$ ( median, IQR) & $193(153 \sim 258)$ & $175(109 \sim 200)$ & $<.001$ \\
RV-PA conduit size, $\mathrm{mm}$ (median, IQR) & $14.0(13.5 \sim 14.0)$ & $12.0(10.0 \sim 12.0)$ & $<.001$ \\
Indexed conduit size, mm ${ }^{2} / \mathrm{m}^{2}$ (median, IQR) & $34.8(30.1 \sim 37.8)$ & $50.0(45.5 \sim 54.5)$ & \\
\hline
\end{tabular}

$G A$ gestational age, $I Q R$ Inter-quartile range, $P R$ primary repair, $R V$ - $P A$ right ventricle to pulmonary artery, $S D$ standard deviation, $S R$ staged repair 
re-intervention. Unadjusted comparisons of the freedom from time-related events between the two groups were conducted using log-rank test. Cox proportional hazards models were fitted to identify the risk factors for the decreased time from the initial surgical intervention to death/1st post-repair re-intervention and death/2nd reintervention, respectively. For the inter-group comparison of death or multiple re-interventions, the Prentice, Williams, and Peterson (PWP) model was used. Statistical significance was defined as a $p$ value less than 0.05. All statistical analyses were conducted using $\mathrm{R}$ version 3.5.3.

\section{Results}

There were three post-palliation in-hospital mortalities, four inter-stage mortalities, and one post-repair in-hospital mortality in group-SR. In group-PR, there was one inhospital death and one late death. Outcomes of all patients according to the surgical strategies are summarized in Fig. 1, and demographic profiles of the mortality cases with causes of death are summarized in Table 2. Fiveyear-survival rates of group-SR and group-PR were $83.6 \%$ and $86.7 \%$, respectively, without a significant inter-group difference ( $p=0.756$, Fig. 2 ). Median ventilatory support time (3 days, IQR: 2-4 days, in group-SR; 6 days,
Fig. 1 Outcomes of 65 patients with PA with VSD according to the surgical strategy. PA pulmonary atresia, $V S D$ ventricular septal defect

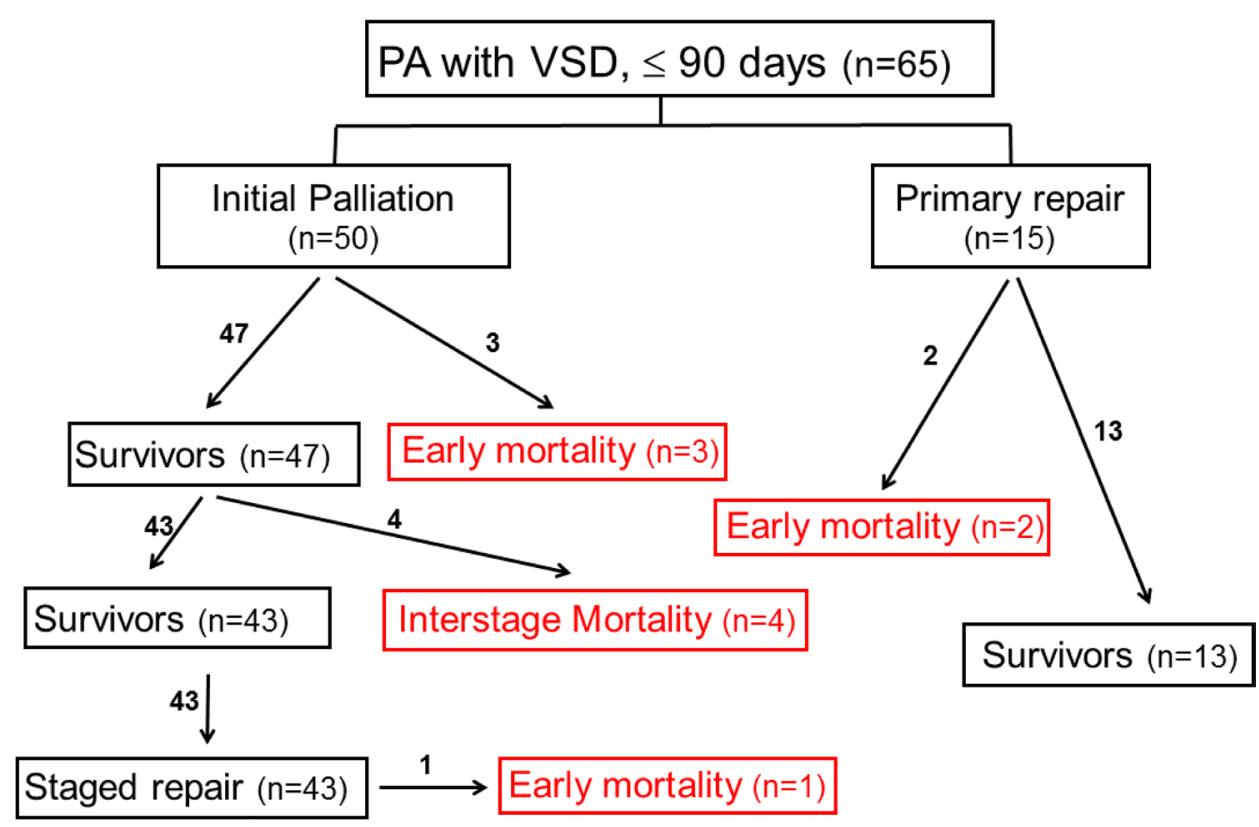

Table 2 Characteristics of mortality cases and causes of death

\begin{tabular}{|c|c|c|c|c|c|c|c|}
\hline Group & Birth weight & Age at initial op & Weight at op & Initial op & Age at death & Mortality type & Cause of death \\
\hline SR & $1.2 \mathrm{~kg}$ & 60 days & $2.5 \mathrm{~kg}$ & RV-PA conduit & 106 days & PPHD & Esophageal bleeding after TEF repair \\
\hline SR & $1.6 \mathrm{~kg}$ & 42 days & $2.8 \mathrm{~kg}$ & RMBT & 49 days & PPHD & Sepsis \\
\hline SR & $3.2 \mathrm{~kg}$ & 11 days & $3.3 \mathrm{~kg}$ & RV-PA conduit & 12 days & PPHD & Pulmonary overflow \\
\hline SR & $2.5 \mathrm{~kg}$ & 17 days & $3.0 \mathrm{~kg}$ & RMBT & 9.4 months & ISD & Pneumonia \\
\hline SR & $2.5 \mathrm{~kg}$ & 16 days & $3.3 \mathrm{~kg}$ & RMBT & 3.3 months & ISD & Unknown \\
\hline SR & $3.1 \mathrm{~kg}$ & 19 days & $3.3 \mathrm{~kg}$ & RMBT & 2.3 months & ISD & Unknown \\
\hline SR & $2.5 \mathrm{~kg}$ & 35 days & $3.6 \mathrm{~kg}$ & RMBT & 3.8 months & ISD & Pulmonary overflow \\
\hline SR & $3.1 \mathrm{~kg}$ & 15 days & $3.3 \mathrm{~kg}$ & RMBT & 85 days & PRHD & $\begin{array}{l}\text { Low cardiac output after staged } \\
\text { repair }\end{array}$ \\
\hline PR & $3.1 \mathrm{~kg}$ & 6 days & $3.4 \mathrm{~kg}$ & Rastelli-type repair & 2.9 months & PRHD & Hypoxic brain damage \\
\hline PR & $3.0 \mathrm{~kg}$ & 16 days & $3.4 \mathrm{~kg}$ & Rastelli-type repair & 4.1 months & PRLD & Unknown \\
\hline
\end{tabular}

$I S D$ inter-stage death, $P P H D$ post-palliation in-hospital death, $O p$ operation, $P R$ primary repair, $P R H D$ post-repair in-hospital death, $P R L D$ postrepair late death, $R M B T$ right modified Blalock-Taussig shunt, $R V$ - $P A$ right ventricle to pulmonary artery, $S R$ staged repair, $T E F$ tracheoesophageal fistula 
Fig. 2 Post-natal survival in the two groups with different surgical strategies. $P R$ primary repair, $S R$ staged repair

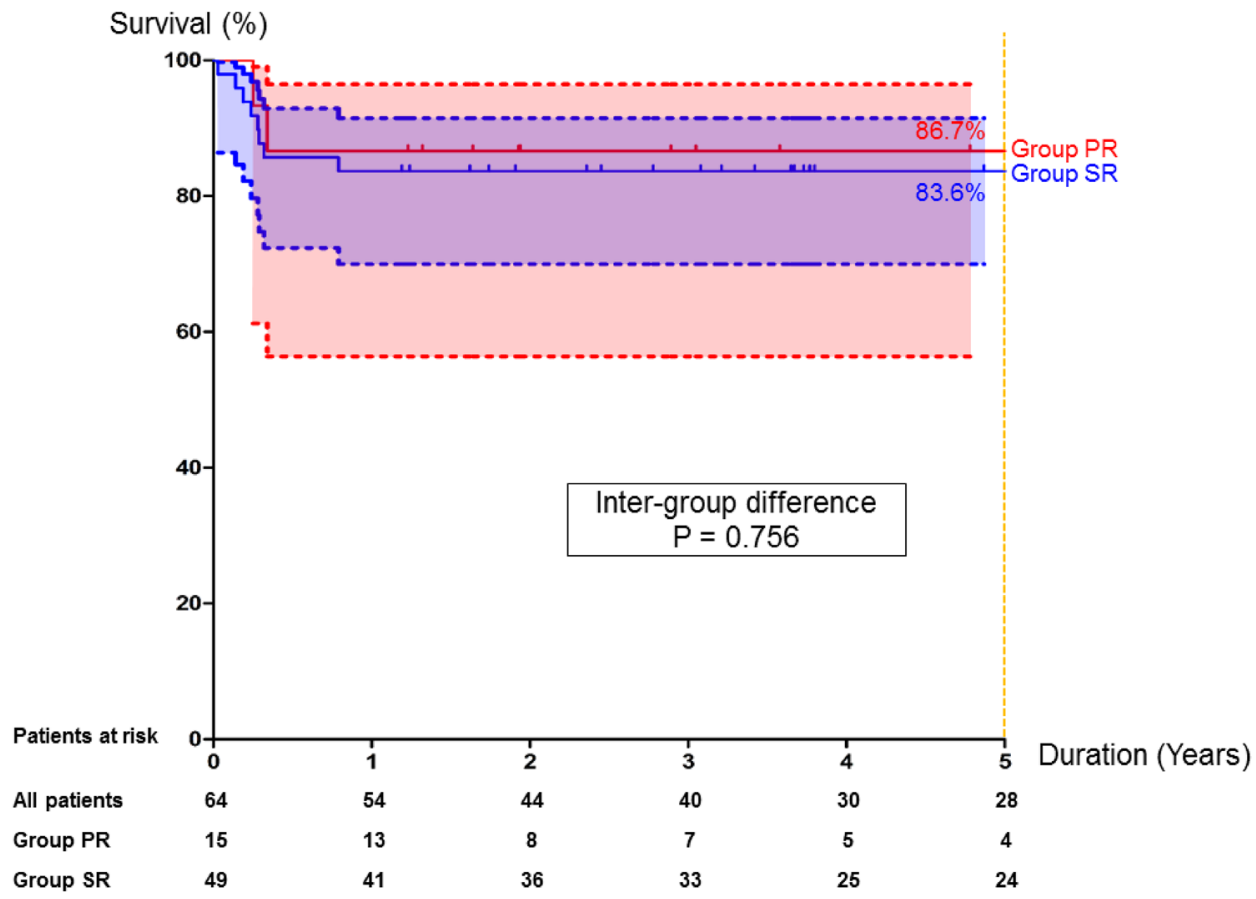

IQR: 5-12 days, in group-PR, $p=0.095)$, median intensive care unit stay (4.5 days, IQR: $3-7$ days, in groupSR; 9 days, IQR: 7-15 days, in group-PR, $p=0.063$ ), and median hospital stage (10 days, IQR: 8-13 days, in group-SR; 17 days, IQR: 13-30, days, in group-PR, $p=0.029)$ after initial operation appeared to be longer in group-PR compared to group-SR. Follow-up was complete in $98.5 \%$ (64/65) of patients. Median follow-up durations in all patients, in group-PR, and group-SR were 44.7 months (IQR: 19-109 months), 33.8 months (IQR: 15-68 months), and 59.3 months (IQR: 22-115 months), respectively.

\section{Post-repair Re-interventions}

Post-repair re-intervention included numerous surgical or catheter-based interventions after Rastelli-type repair. During the median follow-up period, 40 post-repair re-interventions (22 in group-SR, 18 in group-PR) were performed for 26 patients (18 in group-SR, 8 in group-PR). Six patients (two in group-SR, four in group-PR) underwent two reinterventions, and four patients (one in group-SR, three in group-PR) underwent three re-interventions. Details of post-repair re-interventions are summarized in Table 3. Freedom from death or 1st re-intervention at 5 years was $61 \%$ in group-SR and 39\% in group-PR with a significant intergroup difference ( $p=0.044)$ (Fig. 3). Freedom from death
Table 3 Surgical and catheter re-interventions after Rastellitype repair

\begin{tabular}{lccr}
\hline Post-repair re-interventions & Group-SR $(n=43)$ & Group-PR $(n=15)$ & $p$ value \\
\hline Surgical re-intervention & 12 & 6 & 0.74 \\
RV-PA conduit replacement & 2 & 0 & $>0.99$ \\
Peel operation using the back wall of previous & & 3 & 0.06 \\
RV-PA conduit & 0 & 1 & 0.26 \\
RVOTO relief & 0 & & \\
Branch PA angioplasty & & 2 & $>0.99$ \\
Catheter re-intervention & 5 & 6 & 0.003 \\
Ballooning/stenting of the RV-PA conduit & 2 & 0 & $>0.99$ \\
Ballooning/stenting of branch PA stenosis & 1 & 18 & 0.55 \\
SVC ballooning & 22 & & \\
Total & & & \\
\hline
\end{tabular}

$P A$ pulmonary artery, $P R$ primary repair, $R V O T O$ right ventricular outflow tract obstruction, $R V$ - $P A$ right ventricle to pulmonary artery, $S R$ staged repair, $S V C$ the superior vena cava 
Fig. 3 Freedom from death or 1st post-repair re-intervention in two groups with different surgical strategies. $P R$ primary repair, $S R$ staged repair

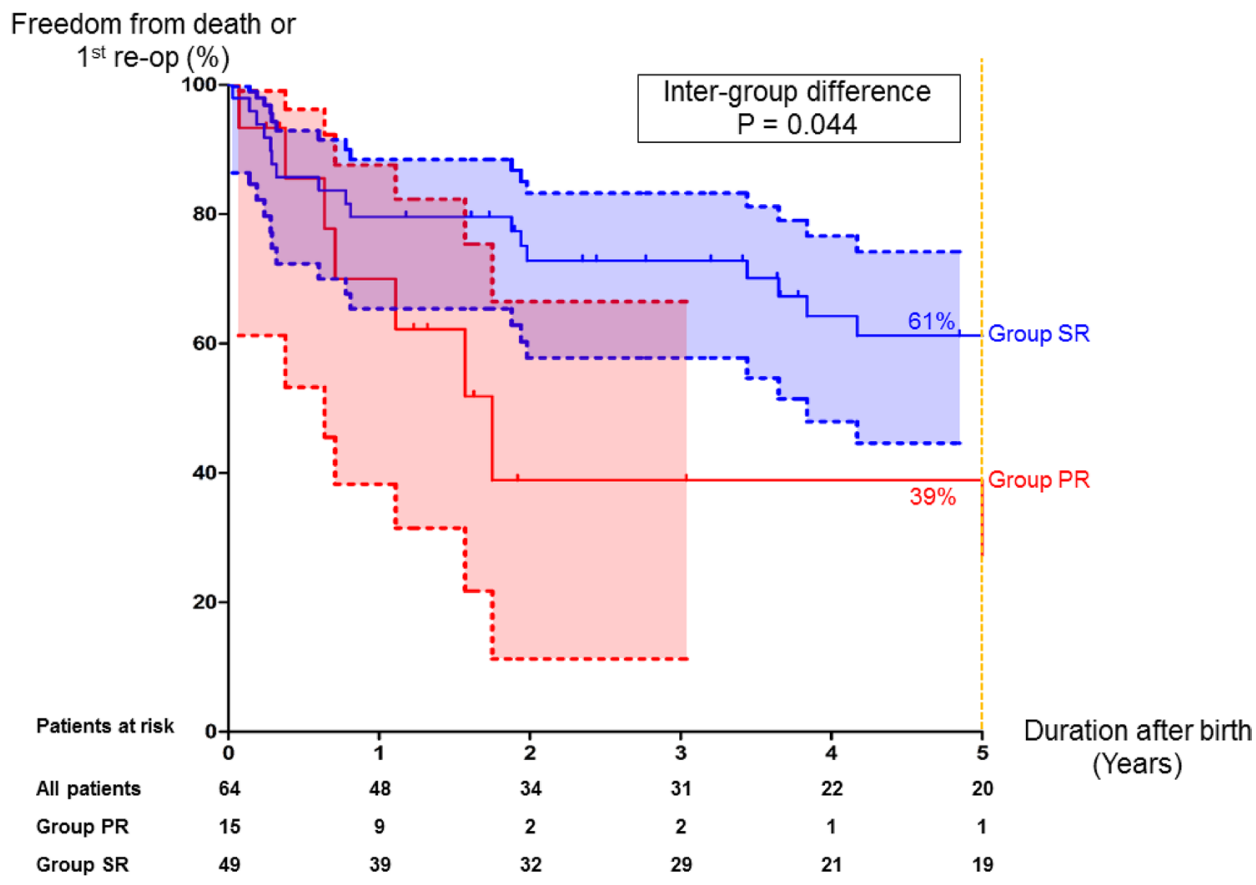

or 2 nd re-intervention at 5 years was $77 \%$ in group-SR and $34 \%$ in group-PR with a significant inter-group difference $(p=0.026)$ (Fig. 4).

When analyzing the risk factors for decreased time to adverse events using the Cox proportional hazards model, group-PR (against group-SR) was the only significant risk factor for decreased time to death or 1st re-intervention (HR 2.3, 95\% confidence interval (CI): 1.00-5.45, $p=0.049$ ) and death or 2nd re-intervention (HR 2.91, 95\%
CI 1.09-7.75, $p=0.033$ ) (Tables4, 5). The chronological depiction of all adverse events in the two groups is presented in Fig. 5. When the PWP recurrent event model was fitted to further analyze the difference between the two groups in terms of the frequency and interval of all adverse events (i.e., death or any re-intervention after birth), patients in group-PR turned out to experience significantly frequent adverse events with shorter intervals compared to group-SR (Table 6).
Fig. 4 Freedom from death or 2nd post-repair re-intervention in two groups with different surgical strategies. $P R$ primary repair, $S R$ staged repair

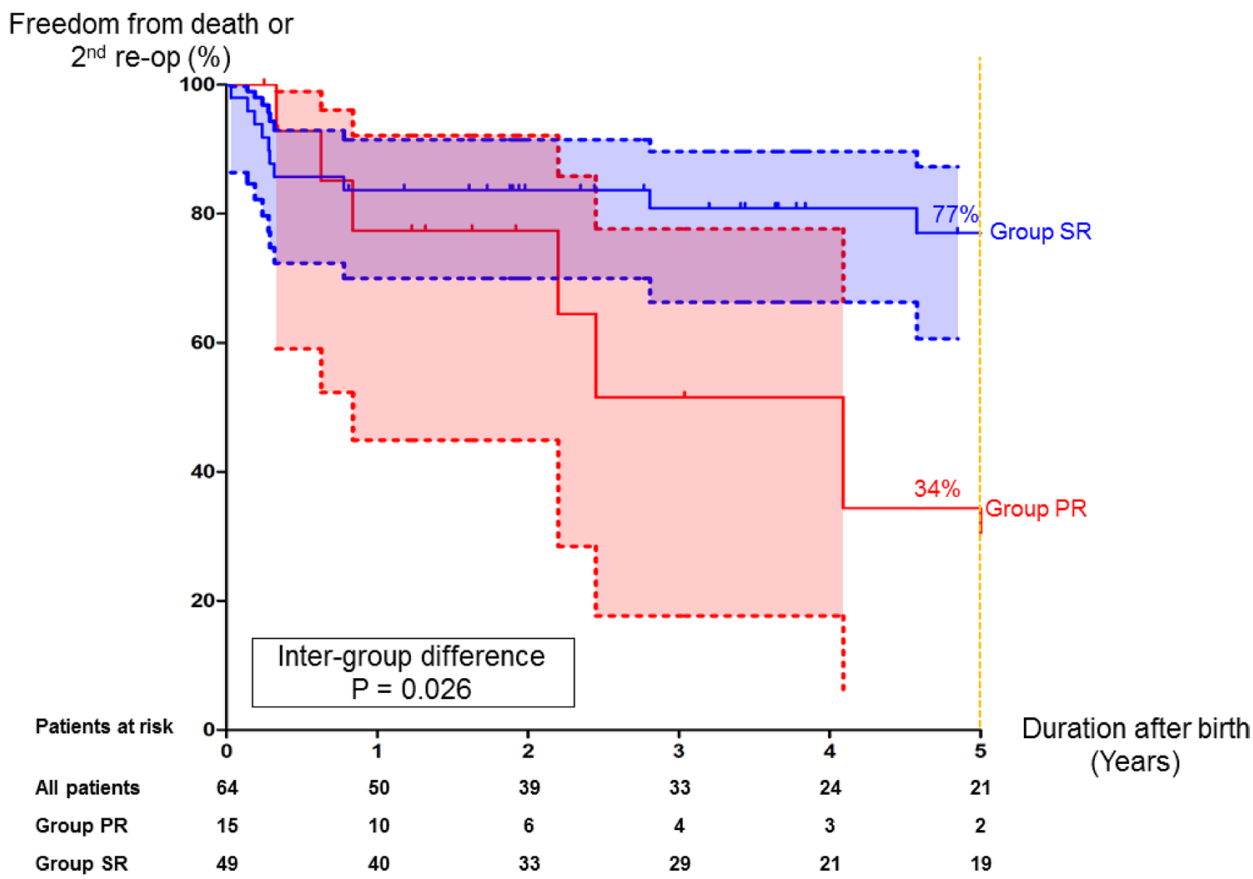


Table 4 Cox proportional hazards model for decreased time to death or $1 \mathrm{st}$ re-intervention
Table 5 Cox proportional hazards model for decreased time to death or 2 nd re-intervention

\begin{tabular}{lllll}
\hline & Univariate & \multicolumn{3}{l}{ Multivariate analysis } \\
\cline { 4 - 5 } & $p$ value & HR & 95\% CI & $p$ value \\
\hline Sex (female) & 0.350 & & \\
Prematurity & 0.162 & & \\
Juxtaductal stenosis & 0.683 & & \\
Nakata index $\left(\mathrm{mm}^{2} / \mathrm{m}^{2}\right)$ at initial operation & 0.311 & & \\
Nakata index $\left(\mathrm{mm}^{2} / \mathrm{m}^{2}\right)$ at repair & 0.180 & & & \\
Preoperative ventilator care & 0.182 & & & \\
Group-PR (against group-SR) & 0.049 & 2.3 & $1.00-5.45$ & 0.049 \\
\hline
\end{tabular}

$C I$ confidence interval, $H R$ hazard ratio, $P R$ primary repair, $S R$ staged repair

\begin{tabular}{lllll}
\hline & Univariate & \multicolumn{3}{l}{ Multivariate analysis } \\
\cline { 4 - 5 } & $p$ value & HR & $95 \%$ CI & $p$ value \\
\hline Sex (female) & 0.934 & & \\
Prematurity & 0.340 & & \\
Juxtaductal stenosis & 0.581 & & \\
Nakata index $\left(\mathrm{mm}^{2} / \mathrm{m}^{2}\right)$ at initial operation & 0.250 & & & \\
Nakata index $\left(\mathrm{mm}^{2} / \mathrm{m}^{2}\right)$ at repair & 0.351 & & & \\
Preoperative ventilator care & 0.158 & & & \\
Group-PR (against group-SR) & 0.033 & 2.91 & $1.09-7.75$ & 0.033 \\
\hline
\end{tabular}

$C I$ confidence interval, $H R$ hazard ratio, $P R$ primary repair, $S R$ staged repair

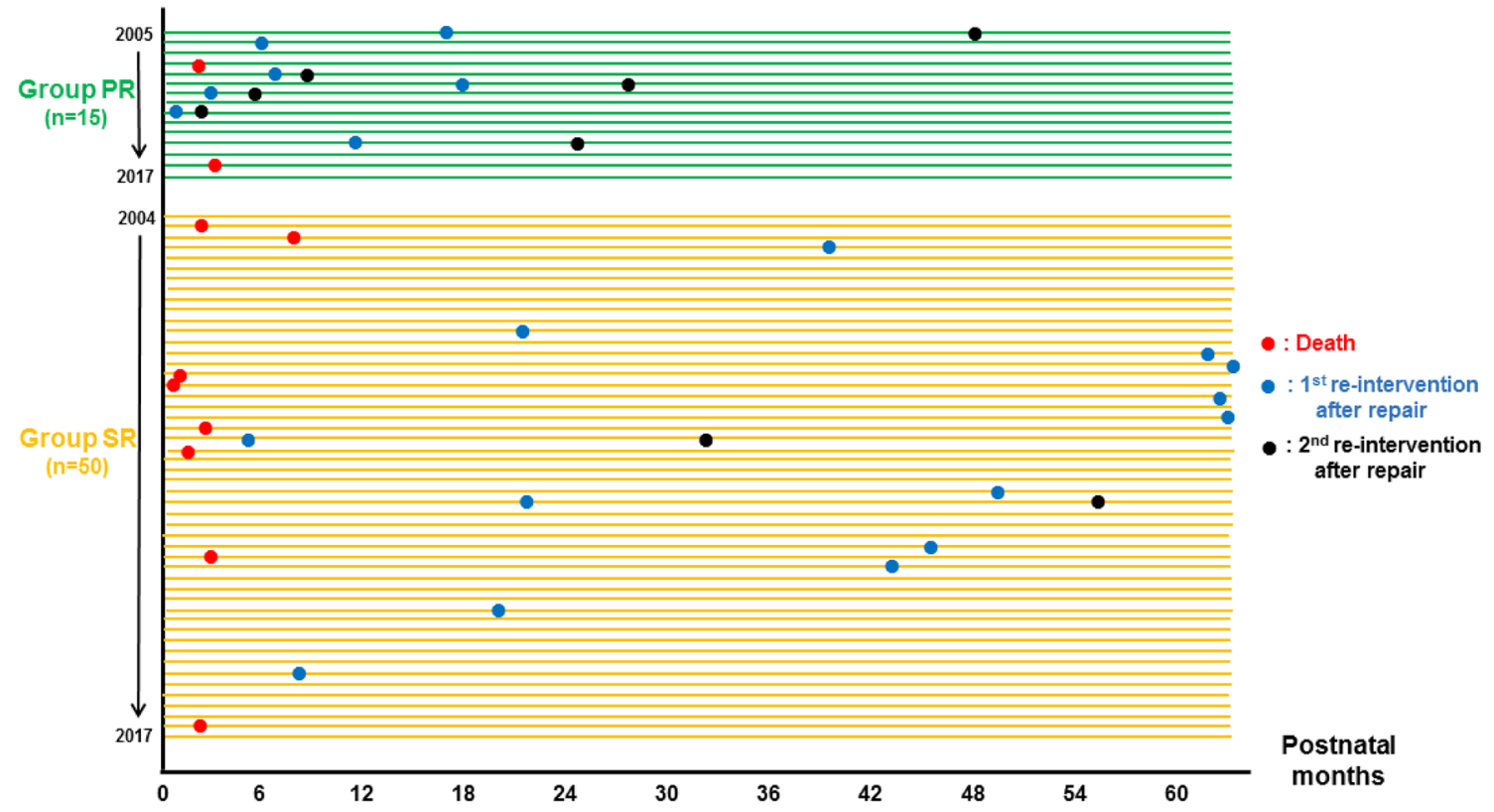

Fig. 5 Chronological plotting of death (red dots), 1st post-repair re-intervention (blue dots), and 2nd post-repair re-intervention (black dots) in two groups with different surgical strategies. $P R$ primary repair, $S R$ staged repair 
Table 6 Risk factor analysis for death or repeated re-interventions (PWP model)

\begin{tabular}{llll}
\hline & HR & $95 \% \mathrm{CI}$ & $p$ value \\
\hline $\begin{array}{l}\text { Total time approach } \\
\text { Group-SR }\end{array}$ & 1 & & \\
Group-PR & 3.64 & $1.39-9.52$ & 0.0086 \\
$\begin{array}{l}\text { Gap time approach } \\
\text { Group-SR }\end{array}$ & 1 & & \\
Group-PR & 4.10 & $1.62-10.42$ & 0.003 \\
\hline
\end{tabular}

$C I$ confidence interval, $H R$ hazard ratio, $P R$ primary repair, $P W P$ Prentice, Williams, and Peterson, $S R$ staged repair

\section{Discussion}

Determination of optimal surgical strategies for complex congenital heart anomalies during the neonatal period is still controversial. For example, ideal surgical options for symptomatic neonates with tetralogy of fallot (ToF) are not fully established. Although excellent results after elective repair of ToF during young infancy are reported [7], current practice for symptomatic neonates with ToF is still either early primary repair or palliation [8-11]. In patients with PA/VSD, initial post-natal palliation with staged repair is more frequently practiced than performing an early primary repair. However, high operative [2] and inter-stage mortality [3-5] rates following a palliative procedure may be a rationales for attempting an initial primary repair. Inter-stage mortality after systemic-to-pulmonary shunt is usually attributed to thrombotic occlusion of the graft, which could be more detrimental in patients with pulmonary atresia than in patients with pulmonary stenosis or additional collateral blood flow [12]. However, an initial primary repair strategy also entails taking risks such as the use of cardiopulmonary bypass for very small and premature babies, possible post-ischemic right ventricular dysfunction, and inevitable placement of a relatively smaller RV-PA conduit [13]. Although the possible detriments and possible advantages of each option have been argued, there have been limited studies comparing the two different surgical options, especially in terms of long-term risks of death or re-interventions.

Concerning the outcomes after a palliative shunt, there have been some studies with inconsistent and debatable results. A study utilizing the Society of Thoracic Surgeons (STS) database from the contemporary series showed that, among the 9,172 infants with systemic artery (or systemic ventricle)-to-pulmonary artery shunt, in-hospital shunt failure occurred in 674 (7.3\%) patients [2]. Another retrospective study analyzing data from 173 patients with ToF or PA/VSD with or without MAPCAs showed an in-hospital mortality of $5.2 \%$, and inter-stage mortality of $3.6 \%$ [14]. Our series also showed significantly high in-hospital and inter-stage mortality rates after initial palliation in group-SR.

However, as shown in Fig. 5, the occurrence of such adverse events has decreased in recent years, which is attributed to advancements in ICU care, early employment of anticoagulation [13, 15, 16], and, most importantly, stringent postoperative home monitoring [17-19]. Parents of neonates discharged after a shunt operation are thoroughly educated about the symptoms and signs that may signify the development of shunt failure, and are given a 24-h hotline number for appropriate counseling provided by clinical nurse specialists. Frequent outpatient clinic visits are suggested so that the appropriate anticoagulation regimens can be given to rapidly growing babies who may outgrow the usual dose of anticoagulation. In 2006, we increased the daily dosage of acetylsalicylic acid (ASA) for patients with MBT from $5 \mathrm{mg} /$ $\mathrm{kg}-10 \mathrm{mg} / \mathrm{kg}$, to effectively prevent thrombotic occlusion of the shunt, and also to prevent the under-dosage of ASA by the outgrowth of the patient [20]. In patients who received MBT using small (i.e., $3 \mathrm{~mm}$ or $3.5 \mathrm{~mm}$ ) PTFE grafts, we attempt to minimize the inter-stage period by setting the timing of total correction within 6 months after birth, a point by which the risk of developing of inter-stage adverse outcomes is still low while a sizable RV-PA conduit can be implanted.

Another surgical issue is the presence of juxtaductal stenosis (JDS), which should be considered in the management of PAVSD [21]. Stenosis of the left pulmonary artery by ductal tissue remnants outgrowth is a well-known, common cause of re-intervention for the branch pulmonary arteries in patients with ToF [22]. Increased risks of pulmonary arterial re-interventions in group-PR from this study may also be attributable to the surgical manipulation directly on the ductal tissue that took place at primary repair. Thus, when staged repair strategies for patients with PA/VSD and JDS is contemplated, a surgical protocol of placing systemicto-pulmonary arterial shunts at our institution is placing MBT shunt on the opposite side to the JDS. This is because performing aggressive pulmonary artery angioplasty for JDS by manipulating a thin and fragile pulmonary artery with abundant ductal tissue may jeopardize the integrity of the pulmonary arterial structure later on. We trust that MBT performed contralaterally to the JSD leads to a clear demarcation of the normal pulmonary arterial tissue after the spontaneous closure of the ductus, which may be helpful for the determination of further management of the branch pulmonary artery ipsilateral to the JDS. Mild JDS with a sizable ipsilateral hilar pulmonary artery can be easily managed at repair, and severe JDS with a hypoplastic ipsilateral hilar pulmonary artery can be managed by placing an additional MBT shunt. The rationale of our strategy is based on the inability to visually discern normal arterial tissue from ductal tissue in the presence of ductal patency. 


\section{Limitations of the Study}

This is a retrospective study of the non-randomized data from a single institution. Although demographic profiles of the patients in the two groups were mostly comparable, patients in group-PR tended to have larger pulmonary arterial size, which might have influenced the decision to perform primary repair. In the analysis of the risk for re-intervention, we did not consider the repair as a re-intervention after initial palliation, which may be disputable to other investigators.

\section{Conclusion}

A staged repair strategy, compared with a primary repair strategy, was associated with comparable overall survival with less frequent re-interventions after Rastelli-type repair. Lowering inter-stage mortality rates after initial palliation by vigilant outpatient care and aggressive home monitoring may be the key to better surgical outcomes.

Funding No funding was provided for this study.

\section{Compliance with Ethical Standards}

Conflict of interest None of the authors has a financial relationship with a commercial entity with interest in the subject matter of this manuscript or other conflicts of interest to disclose.

\section{References}

1. Tchervenkov CI, Roy N (2000) Congenital heart surgery nomenclature and database project: pulmonary atresia—ventricular septal defect. Ann Thorac Surg 69(4 suppl):S97-105

2. Do N, Hill KD, Wallace AS et al (2018) Shunt failure-risk factors and outcomes: an analysis of the Society of Thoracic Surgeons Congenital Heart Surgery Database. Ann Thorac Surg 105(3):857-864

3. Amark KM, Karamlou T, O'Carroll A et al (2006) Independent factors associated with mortality, reintervention, and achievement of complete repair in children with pulmonary atresia with ventricular septal defect. J Am Coll Cardiol 47(7):1448-1456

4. Alsoufi B, Mori M, McCranken C et al (2015) Results of primary repair versus shunt palliation in ductal dependent infants with pulmonary atresia and ventricular septal defect. Ann Thorac Surg 100(2):639-646

5. Kwak JG, Lee CH, Lee C, Park CS (2011) Surgical management of pulmonary atresia with ventricular septal defect: early total correction versus shunt. Ann Thorac Surg 91(6):1928-1934

6. Kim H, Sung SC, Chang YH, Lee HD, Park JA (2013) A new simplified technique for making tricuspid expanded polytetrafluoroethylene valved conduit for right ventricular outflow reconstruction. Ann Thorac Surg 95(5): e131-133
7. Walsh EP, Rockenmacher S, Keane JF, Hougen TJ, Lock JE, Castaneda AR (1988) Late results in patients with tetralogy of Fallot repaired during infancy. Circulation 77(5):1062-1067

8. Woldu KL, Arya B, Bacha EA, Williams IA (2014) Impact of neonatal versus nonneonatal total repair of tetralogy of Fallot on growth in the first year of life. Ann Thorac Surg 98(4):1399-1404

9. Kanter KR, Kogon BE, Kirshbom PM, Carlock PR (2010) Symptomatic neonatal tetralogy of Fallot: repair or shunt? Ann Thorac Surg 89(3):858-863

10. Karl TR, Sano S, Pornviliwan S, Mee RB (1992) Tetralogy of Fallot: favorable outcome of nonneonatal transatrial, transpulmonary repair. Ann Thorac Surg 54(5):903-907

11. Fraser CD Jr, McKenzie ED, Cooley DA (2001) Tetralogy of Fallot: surgical management individualized to the patient. Ann Thorac Surg 71(5):1556-1561

12. Alsoufi B, Gillespie S, Mori M, Clabby M, Kanter K, Kogon B (2016) Factors affecting death and progression towards next stage following modified Blalock-Taussig shunt in neonates. Eur J Cardiothorac Surg 50(1):169-177

13. Farouk A, Zahka K, Siwik E et al (2009) Individualized approach to the surgical treatment of tetralogy of Fallot with pulmonary atresia. Cardiol Young 19(1):76-85

14. Hobbes B, d'Udekem Y, Zannino D, Konstantinov IE, Brizard C, Brink J (2017) Determinants of adverse outcomes after systemicto-pulmonary shunts in biventricular circulation. Ann Thorac Surg 04(4):1365-1370

15. Wessel DL, Berger F, Li JS et al (2013) Clopidogrel in infants with systemic-to-pulmonary-artery shunts. N Engl J Med 368(25):2377-2384

16. Heidari-Bateni G, Norouzi S, Hall M, Brar A, Eghtesady P (2014) Defining the best practice patterns for the neonatal systemic-topulmonary artery shunt procedure. J Thorac Cardiovasc Surg 147(3):869-873

17. Öhman A, Strömball-Larseeon E, Nilsson B, Mellander M (2013) Pulse oximetry home monitoring in infants with single-ventricle physiology and a surgical shunt as the only source of pulmonary blood flow. Cardiol Young 23(1):75-81

18. Oster ME, Enrlich A, King E et al (2015) Association of interstage home monitoring with mortality, readmissions, and weight gain: a multicenter study from the National Pediatric Cardiology Quality Improvement Collaborative. Circulation 132(6):502-508

19. Siehr SL, Norris JK, Bushnell JA et al (2014) Home monitoring program reduces interstage mortality after the modified Norwood procedure. J Thorac Cardiovasc Surg 147(2):718-723

20. Li JS, Yow E, Berezny KY et al (2007) Clinical outcomes of palliative surgery including a systemic-to-pulmonary artery shunt in infants with cyanotic congenital heart disease: does aspirin make a difference? Circulation 116(3):293-297

21. Elzenga NJ, von Suylen RJ, Frohn-Mulder I, Essed CE, Bos E, Quaegebeur JM (1990) Juxtaductal pulmonary artery coarctation. An underestimated cause of branch pulmonary artery stenosis in patients with pulmonary atresia or stenosis and a ventricular septal defect. J Thorac Cardiovasc Surg 100(3):416-424

22. Jang WS, Kim WH, Cho SK (2017) Effects of angle correction angioplasty for pulmonary artery stenosis with tetralogy of Fallot. Ann Thorac Surg 103(3):862-868

Publisher's Note Springer Nature remains neutral with regard to jurisdictional claims in published maps and institutional affiliations. 